archives

of thermodynamics

Vol. 33(2012), No. 2, 3-22

DOI: $10.2478 / \mathrm{v} 10173-012-0008-\mathrm{x}$

\title{
Heat transfer during condensation of refrigerants in tubular minichannels
}

\author{
TADEUSZ BOHDAL* \\ HENRYK CHARUN \\ MAEGORZATA SIKORA
}

Koszalin University of Technology, Racławicka 15-17, 75-620 Koszalin, Poland

\begin{abstract}
The present paper describes the results of experimental investigations of heat transfer during condensation of R134a, R404A and R407C in pipe minichannels with internal diameters $0.31-3.30 \mathrm{~mm}$. The results concern investigations of the local heat transfer coefficient. The results were compared with the correlations proposed by other authors. Within the range of examined parameters of the condensation process in minichannels made of stainless steel, it was established that the values of the heat transfer coefficient may be described with Akers et al., Mikielewicz and Shah correlations within a limited range of the mass flux density of the refrigerant and the minichannel diameter. On the basis of experimental investigations, the authors proposed their own correlation for the calculation of local heat transfer coefficient.
\end{abstract}

Keywords: Condensation in minichannels; Heat transfer; Compact condenser; Refrigeration

\section{Nomenclature}
$A \quad-$ heat transfer area, $\mathrm{m}^{2}$
$d \quad-\quad$ minichannel inner diameter, $\mathrm{m}$
$d_{h} \quad-$ hydraulic diameter, $\mathrm{m}$
$G \quad-\quad$ mass flux density, $\mathrm{kg} / \mathrm{m}^{2} \mathrm{~s}$
$j_{v} \quad-$ dimensionless vapour velocity

\footnotetext{
${ }^{*}$ Corresoponding author. E-mail address: Tadeusz.Bohdal@tu.koszalin.pl
} 


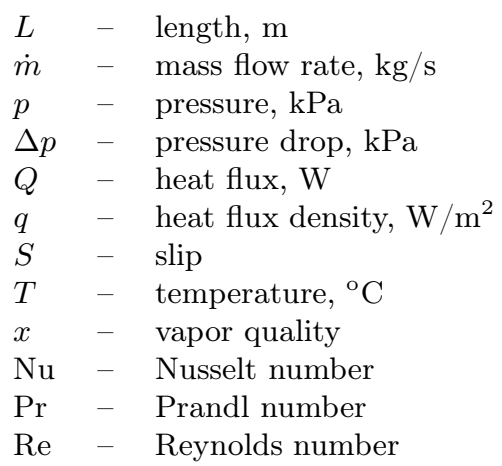

\section{Greek symbols}

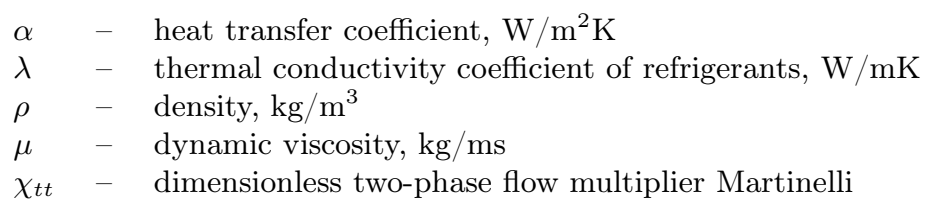

\section{Subscripts}

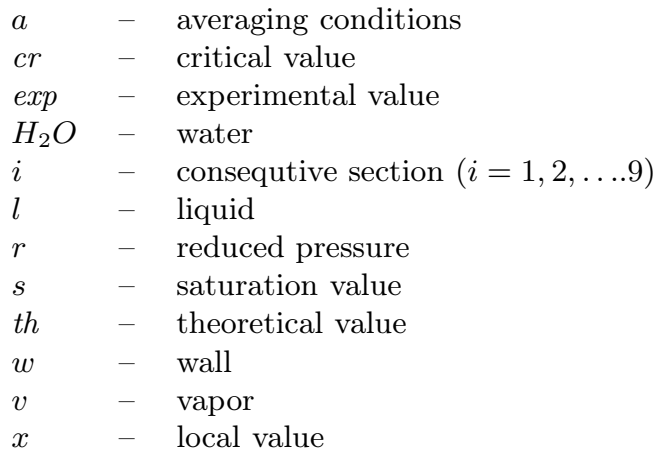

\section{Introduction}

The turn of the twenty-first century saw an abrupt technological advance that was evident in the qualitative and quantitative growth in the production of space technology and electronics devices. These two technologies are inseparable, and they mark a trend toward the miniaturisation of such devices. It is worth noting that the absolute value of thermal power in computer systems is not significantly large, while the density of heat fluxes, i.e., the amount of heat transferred by a field unit of the heat transfer area, reaches substantial values, even as much as $1000 \mathrm{~W} / \mathrm{cm}^{2}$, as indicated by 
Baummer et al. [5]. The traditional methods for transferring such heat flux densities are either minimally useful or not useful at all. A paper by Obhan and Garimella [24] discusses methods presently used and those recommended for the future. In view of the above, the use of two-phase media becomes a priority. The practical realisation of these media involves implementation of the intensification methods of convective heat transfer with phase change. One of the passive methods used to intensify the convective heat transfer process includes, among others, a reduction of the diameter of those channels through which the agent that realises the heat transfer process flows. Increase in the value of heat transfer coefficients serves as a measure of the effectiveness of this intensification. The following criteria need to be fulfilled for the construction of modern refrigeration and air conditioning heat exchangers: small dimensions, high efficiency of heat transfer and the environmentally friendly technology.

For this purpose, the concept of so-called compact heat exchangers (including refrigeration evaporators and condensers) was proposed. In these compact heat exchangers, the ratio of the heat transfer area to the overall volume is greater than $700 \mathrm{~m}^{2} / \mathrm{m}^{3}$, Shah [26]. The fulfilment of this criterion requires the use of channels with hydraulic diameters $d_{h}=1-6 \mathrm{~mm}$. Such a criterion was proposed by Mehendale et al. [20]. At present, the classification proposed by Kandlikar [17] is commonly used. This classification specifies in detail the measurements of channels in the construction of heat exchangers. According to this classification, the following can be used in compact exchangers: for microchannels, $d_{h}=10-200 \mu \mathrm{m}$; for minichannels, $d_{h}=200 \mu \mathrm{m}-3 \mathrm{~mm}$. In comparison, conventional channels have hydraulic diameters $d_{h} \geq 3 \mathrm{~mm}$.

Recent years have seen an increased interest and a growing number of papers about heat and flow processes in compact exchangers where channels are used with dimensions smaller than conventional ones, Thome [32], Kandlikar et al. [18], Giaasian [15], Mikielewicz [22]. Also, the number of studies concerning heat transfer and flow resistance in channels with small diameters is growing as is the number of studies that deal with the condensation process. One of the reasons for this increased interest might be that, initially, the boiling and condensation phenomena in these types of channels were treated as being symmetrical to each other, which, even concerning the flow in conventional channels, proved to be too great of a simplification, Mikielewicz [21]. This problem was confirmed in papers by Thome et al. $[33,34]$, which presented a new heat transfer model in horizontal pipes appli- 
cable to hydraulic diameters $d_{h}=3.1-21.4 \mathrm{~mm}$, and in Cavallini et al. [9], who dealt with heat transfer in minichannels. Many authors warn against transferring to micro- and minichannels those correlations that have been specified and verified for the flow with the phase change in conventional channels. However, it is also to be noted that the correlations developed for low- or medium-pressure refrigerants (e.g. R134a) do not have to be appropriate for high-pressure refrigerants such as R404A and R410A.

Designing compact heat exchangers is also made difficult because, according to the present state of knowledge, there is no unequivocal indication of a unified model of the condensation of refrigerants in micro- and minichannels. Investigations concerning the realisation of this postulate are being conducted in many countries, while an introductory attempt to summarise these was provided, among others, in papers by Sun and Mishima [27] and Garcia-Cascales et al. [14].

This study presents research problems that occur in compact condensers with refrigerant R134a. Homogenous refrigerant R134a belongs to the hydrofluorocarbon (HFC) group and is one of the substitutes of R12, while the near-azeotropic mixture (composed of three refrigerants from the HFC group: R134a, R125 and R134a) is a substitute for R22. On 1 January 2010, R22 freon was withdrawn from active application in refrigeration technology (it is still possible to service devices that were designed prior to that date).

\section{Selection of the proper correlation for the calcu- lation of heat transfer coefficients}

When designing a compact condenser composed of minichannels, the same engineering problems need to be solved as in a conventional condenser. This task involves the calculation of the required available heat exchange area and the driving power of the movement generators of those agents that realise the heat exchange process. To this end, it is necessary to have access to information concerning the establishment of heat transfer coefficients from the side of the refrigerants, i.e. the condensing and refrigerating agents, as well as the flow resistances of both these agents. The determination of these values for the refrigerant is relatively simple, but for the phase change during condensation, especially in the flow in a minichannel, it is difficult [7].

In papers concerning condensation in minichannels, the following issues of heat exchange and flow resistance are addressed: 
1. The flow takes place in a single smooth pipe minichannel with a circular or noncircular section.

2. The flow occurs in a multichannel system, which is composed of several to several dozen parallel channels that are fed at the same time.

3. The flow takes place in channels with internal fins and with a small diameter (e.g., with microfins on the internal surface) in systems with single channels and with many channels.

4. The structure of the two-phase flow dominating the condensation process in the minichannel must be determined.

The issues presented above do not exhaust all the problems, including the problems of great importance, such as the impact of the shape of the section of the hydraulic diameter of the channel or the refrigerant type. Computational correlations are generally proposed in one of two forms:

1. An adaptation of those correlations that were verified for conventional channels in relation to minichannels.

2. Proposals of new correlations that are based on investigations (theoretical or experimental) conducted with the use of minichannels.

The following correlations are useful in the calculations of heat exchange during condensation in conventional channels and that can be adopted for minichannels: Akers et al. [2,3], Dobson and Chato [13], Shah [26], Cavallini and Zecchin [10], Tang [31], Thome et al. [33,34].

At the same time, a growing number of papers deal with the results of investigations into heat exchange in mini- and microchannels. The research conducted by Yang and Webb [35] and Yan and Lin [35] confirmed that in comparable ranges of condensation parameters, the values of heat transfer coefficient in minichannels are higher, by at least $10 \%$, than the values obtained in conventional channels. In addition, the decrease of minichannel diameter leads to increase of the heat transfer coefficient, which is usually accompanied by the increase of flow resistance.

According to the present trends, Garcia-Cascales et al. [14], the results of these investigations are particularly important for the construction of computational correlations for the determination of the values of heat transfer coefficient, $\alpha$, where the influence of surface tension in minichannels and the capillarity effect in micro- and nanochannels is taken into account. In this area, recent studies by Tabatabai and Faghri [29] as well as Akbar et al. [1] are noteworthy. Papers by Yang and Webb [36], Bandhauer et al. [4] 
and Cavallini et al. [9] are also of particular significance. On the basis of an extended database of various researchers, Garcia-Cascales et al. [14], that are presently interesting and worth recommending for the calculation of the heat transfer coefficient, were developed by Webb et al. [38], Wang et al. [37], and Koyama et al. [19]. Previously developed correlations proposed by Akers et al. [2,3] and Shah [26] can also be used in suitably defined ranges. The abovementioned correlations were experimentally tested as follows:

- correlation due to Webb et al. [38]: investigations in channels with hydraulic diameter $d_{h}=1.56 \mathrm{~mm}$ and $1.41 \mathrm{~mm}$ (R12, R134a), saturation temperature $T_{s}=65{ }^{\circ} \mathrm{C}$, and mass flux density $400<G<$ $1.400 \mathrm{~kg} /\left(\mathrm{m}^{2} \mathrm{~s}\right)$;

- correlation by Wang et al. [37]: investigations in a rectangular channel $d_{h}=1.46 \mathrm{~mm}(\mathrm{R} 134 \mathrm{a}), T_{s}=61.5-66^{\circ} \mathrm{C}$, and $75<G<750 \mathrm{~kg} /\left(\mathrm{m}^{2} \mathrm{~s}\right)$;

- correlation by Koyama et al. [19]: investigations in a multi-port type channel (R134a), $d_{h}=0.81$ and $0.89 \mathrm{~mm}, T_{s}=60{ }^{\circ} \mathrm{C}$, and $100<$ $G<1300 \mathrm{~kg} /\left(\mathrm{m}^{2} \mathrm{~s}\right)$;

- correlation by Cavallini et al. [9]: investigations in a multiport type channel (R134a, R410A), $T_{s}=40{ }^{\circ} \mathrm{C}$, and $200<G<1000 \mathrm{~kg} /\left(\mathrm{m}^{2} \mathrm{~s}\right)$; correlation by Bandhauer et al. [4]: $d_{h}=0.4-4.9 \mathrm{~mm}$ (R134a) and $150<G<750 \mathrm{~kg} /\left(\mathrm{m}^{2} \mathrm{~s}\right)$.

Apart from the correlations by Akers et al. [2,3] and Shah [26], it also possible to use 'older' correlations, including those due to Dobson and Chato [13], Tandon et al. [30], Moser et al. [23], Tang [31] and Wilson et al. [39]. When making use of any correlation concerning condensation in minichannels, one needs always to refer to the source material of its origin and to compare the process parameters and the range of its verification.

Sometimes researchers have contradictory views concerning the same issue, such as the application of a given correlation in the calculation of the heat transfer coefficient. This problem will be presented in an example of the use of the correlation by Shah [26] and Akers [2,3]. In the paper by Webb et al. [38], the results of the authors' own research were compared with the calculations according to the abovementioned correlations. When taking into account the dependence of coefficient $\alpha$ from the mass flux density, $G$, it was established that the values of this coefficient calculated from Shah's correlation were too high, while those from the correlation by Akers et al. [2,3] were too low in relation to the experimental data. A study by Chang and Wang [12] confirmed the usefulness of Shah's [26] correlation 
in the calculation of coefficient $\alpha$ in minichannels, with low values of quality $x$ (however, this is contradictory to the conclusions provided in the paper by Webb et al. [38]. At the same time, the research by Yan and Lin [35] confirms the observations made by Webb et al. [38]. Numerous authors have remarked that the results of condensation in minichannels are to be treated with a special care for small values of mass flux densities $G<70 \mathrm{~kg} /\left(\mathrm{m}^{2} \mathrm{~s}\right)$ and quality $x<0.5$.

\section{Experimental investigations}

\subsection{Subject of the investigations}

Pipe minichannels with internal diameters $d=0.31-3.30 \mathrm{~mm}$ constituted the subject of investigations. Stainless steel minichannels with internal diameters $d=0.31,0.45,0.64,0.98,1.40,1.60,1.94,2.30$ and $3.30 \mathrm{~mm}$ were used. The sections of these minichannels, with a total length of 1000 $\mathrm{mm}$ (and measuring length $L=950 \mathrm{~mm}$ ), were alternately assembled at the experimental facility.

\subsection{Experimental facility and methodology of investigations}

Figures 1 presents a diagram of the experimental facility, while Fig. 2 provides its overall view. Section 1 of the pipe minichannel was the basic element of the experimental facility. This section was placed in the horizontal axis of water channel 2 , which was made from aluminium with a rectangular cross-section and internal dimensions of $28 \times 24 \mathrm{~mm}$. The refrigerant was supplied to measuring section 1 from the side of pumping compressor 3 of the compressor installation. Before the refrigerant reached the inlet section of the minichannel, its superheated vapour flew through the tubular type exchanger in pipe 10, which was chilled with water. The use of this exchanger allowed not only the collection of superheat but also the preparation of the refrigerant's state in the form of a dry, saturated vapour with a quality $x=1$ (or near this state). After the condensation of the refrigerant's vapour in a flow through a pipe minichannel, the refrigerant's liquid flew to subcooler 11 on the outlet, from which the refrigerant's flow rate was measured with the aid of a Coriolis type flowmeter 15. The refrigerant's flow rate was measured for control purposes with the aid of a system of calibrated vessels. Then, the refrigerant returned to the refrigeration system that was fed from unit 3 with a condenser with chilled air 4 


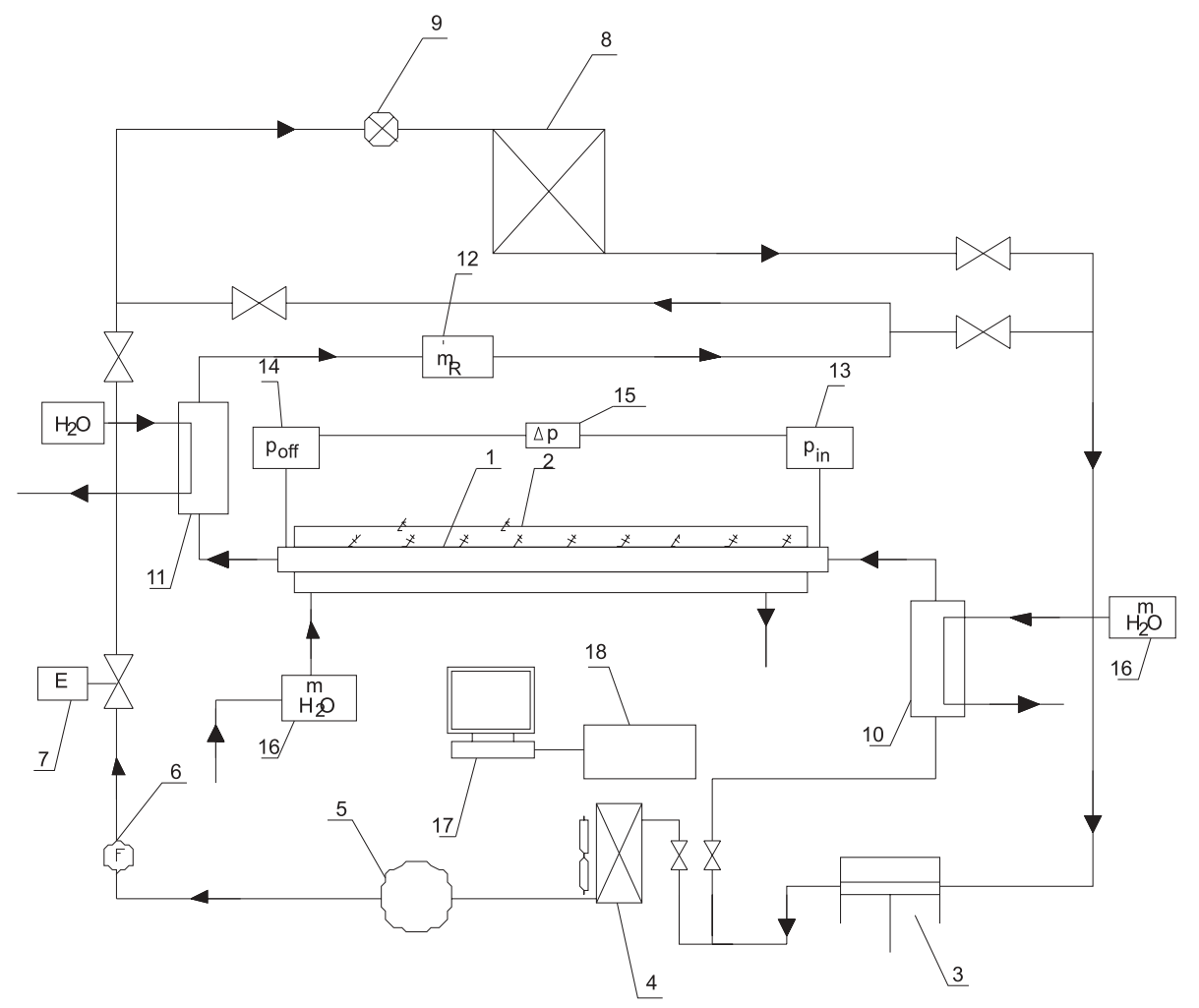

Figure 1. Schematic diagram of the experimental facility: 1 - measuring section of the pipe minichannel, 2 - water channel, 3 - refrigeration compressor installation, 4 - condenser chilled with air, 5 - container of refrigerant liquid, 6 - filter-dryer of refrigerant, 7 - electromagnetic valve, 8 - lamelled air cooler, 9 - expansion valve that feeds the cooler, 10 - heat exchanger to collect refrigerant's superheat, 11 - subcooler of refrigerant's liquid, 12 - electronic flowmeter of refrigerant, 13 - refrigerant's pressure pickup on the inlet to the measuring section, 14 - refrigerant's pressure pickup on the outlet to the measuring section, 15 - refrigerant's differential pressure transducer, 16 - water electronic flowmeter, 17 - computer, 18 - data acquisition system.

and a fan cooler 8.

Figure 3 presents a diagram of measuring section 1 from Fig. 1 with its instrumentation, and Fig. 4 gives its view. Along the length $L=950 \mathrm{~mm}$ of this minichannel section, 9 thermocouples of the $\mathrm{K}$ type were installed that were arranged in even distances for the purpose of measuring the external temperature of the minichannel surface. In each of these nine measuring sections, the temperature of the chilling water that flew into water chan- 


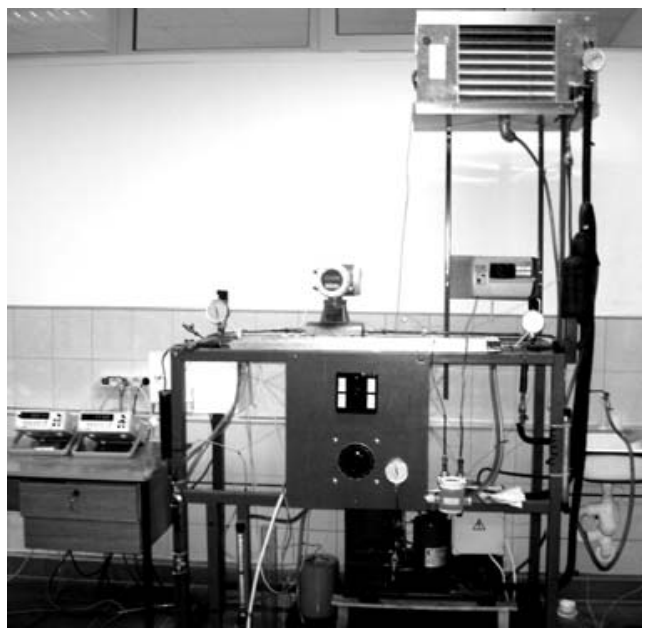

Figure 2. Overall view of the experimental facility.

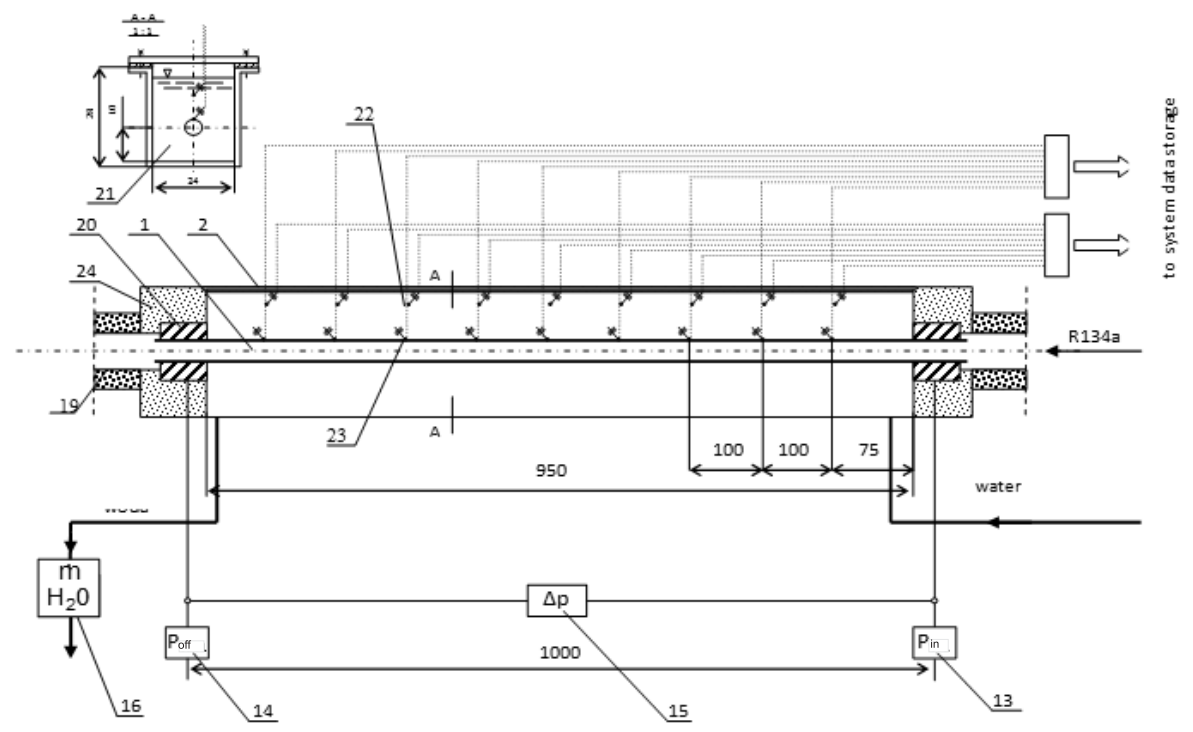

Figure 3. Schematic diagram of the measuring section of the pipe minichannel; $19-$ copper pipe $\phi 8 / \phi 10 \mathrm{~mm}, 20$ - pipe connector, 21 - pipe minichannel refrigeration system, 22 - connector of thermocouple wires of water temperature thermocouples, 23 - connector of thermocouple wires of minichannel surface thermocouples, 24 - isolation; (the remaining denotations are as in Fig. 1). 
nel 2 from Fig. 1 was measured. The thermocouple welds for the water temperature measurement were placed $19 \mathrm{~mm}$ from the bottom of water channel 2 in its vertical axis. The thermocouple wires of the temperature sensors were led to connectors 22 and 23 and to data acquisition system 18 . Before installation, all of the thermocouples were recalibrated in relation to the standard glass thermometer with a $0.05{ }^{\circ} \mathrm{C}$ scale interval. Individual thermoelectric characteristics were made. The pressure of the refrigerants at the inlet to the measuring section was measured with a piezoresistant sensor with a transducer of the class 0.4 , while the pressure drop was measured with the aid of a differential pressure sensor with a transducer of the same class.

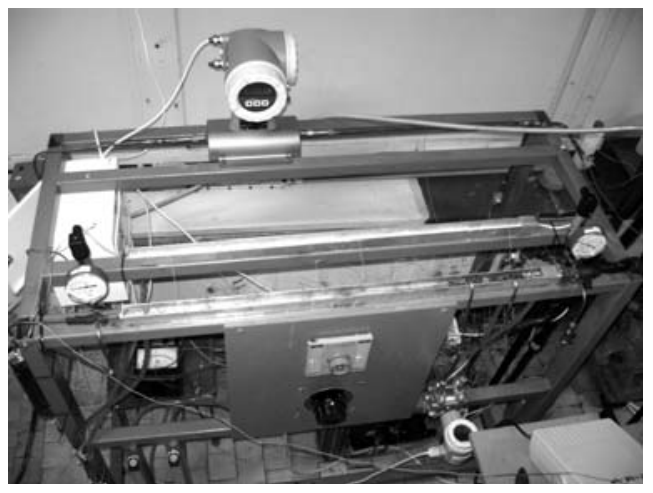

Figure 4. Overall view of measuring section.

Once the tests have been conducted with the pipe minichannel of internal diameter $d$, measurements were conducted for minichannels with other diameters. Electronic flowmeter 16 was used to measure the chilling water flow rate.

The characteristic experimental values of the condensation heat transfer coefficient of R134a, R404A or R407C in a pipe minichannel were determined using the developed procedures. The following were measured directly at the experimental facility: the temperature of the external surface of the minichannel wall in the $i$-th section, $T_{z i}(i=1,2, \ldots 9)$; the flow rate of the refrigerant and its temperature in the inlet and outlet sections of the minichannel; the mass flow rate of chilling water and its temperature in nine sections; the pressure of the refrigerant in these sections; and the pressure drop between the inlet section to the minichannel and a given section. 
At a separate measuring facility, tests were conducted of heat flux, $Q$, which was carried away in the condensation process of the refrigerant on the length $L=950 \mathrm{~mm}$ of the pipe minichannel and its values in each of the 9 sections. For a comparative method of heat flux measurement, an idea proposed by Shin and Kim [27] was used. For this purpose, nine sections were made of minichannels (with different internal diameters $d$ ), each of length $L$. Thermocouples were installed in the individual sections. At a separate facility, the minichannel sections were switched on interchangeably as resistors in an electric circuit. The electric current power was measured, which, after taking into account the heat losses to the environment, enabled determination of heat flux $Q$ (during the measurement, the refrigerant did not flow inside the minichannel). By referring heat flux, to the internal surface of the minichannel, heat flux density, $q,(q=Q / \pi d L)$ was determined. Individual characteristics $q=f\left(T_{w i}-T_{\mathrm{H}_{2} \mathrm{O}, i}\right)$ were made for each measuring section of the minichannel. The temperature of the internal surface of the minichannel in the $i$-th section was denoted as $T_{w i}$. The value of this temperature was determined by knowing the measured value $T_{z i}$ of the external surface and the temperature drop as a result of heat conduction on the thickness of the minichannel wall. The local heat transfer coefficient was calculated from the following dependence: where is the saturation temperature in the $i$-th section. The dryness factor $x$ of the refrigerant's vapour was determined from the energy balance of the heat exchanger denoted with the symbol 10 in Fig. 1 . In the calculation of $x$, the dependence was used that describes the slip between pases $S$ according to Huhn's correlation [16].

\section{Experimental results}

The purpose of experimental tests on the condensation of refrigerants in pipe minichannels with internal diameters $d=0.31-3.30 \mathrm{~mm}$ was to determine the local heat transfer coefficient $\alpha_{x}$. Figure 5 presents, as an example of the results on the investigations of the local heat transfer coefficient the dependence with dryness factor, $\alpha_{x}=f(x)$, during condensation in minichannels with the diameters of $0.31 \mathrm{~mm}$. Figure 6 presents the test results for minichannels with internal diameters $d=0.98-3.30 \mathrm{~mm}$. 


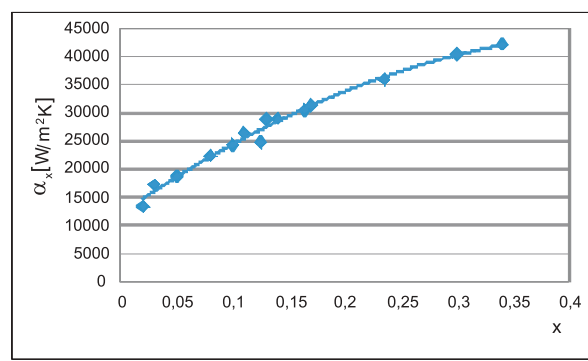

a)

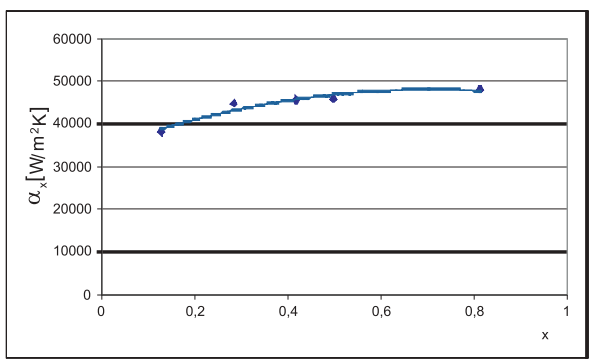

b)

Figure 5. Results of experimental tests of the local heat transfer coefficient during the condensation in pipe minichannels with the diameters of $0.31 \mathrm{~mm}$ : a) R134a, b) R404A.

\subsection{Results of the analysis}

When comparing the results of the authors' own investigations with the results of tests conducted by others, the criteria provided by Cavallini et al. [11] were used. They allow an assessment of the limits of the two-phase flow structures of the condensation of refrigerants in channels with the aid of dimensionless vapour velocity, $j_{v}$, and $\chi_{t t}$, which is the dimensionless two-phase flow multiplier due to Martinelli, as follows:

$$
\begin{gathered}
j_{v}=\frac{G x}{\sqrt{g d \rho_{v}\left(\rho_{l}-\rho_{v}\right)}}, \\
\chi_{t t}=\left(\frac{1-x}{x}\right)^{0.9}\left(\frac{\rho_{v}}{\rho_{l}}\right)^{0.5}\left(\frac{\mu_{l}}{\mu_{v}}\right)^{0.1},
\end{gathered}
$$

where $G$ is the mass flux density, $g$ is the gravitational acceleration, $\rho$ is the density, $\mu$ is the kinematic velocity, $x$ is the quality, and the subscripts $l$ and $v$ refer to liquid and vapour phase, respectively.

In most of the cases, the measurements conducted by the authors were realised for the flow parameters $j_{v} \geq 2.5$ and $\chi_{t t}<1.6$, which involves the possibility of the occurrence of annular or annular and stratified flow structures. Figure 7 presents a comparison of the results of experimental investigations concerning the heat transfer coefficient with the results of calculations from the classical calculations used for conventional channels. The following correlations were taken into account: Dobson and Chato [13], Cavallini and Zecchin [10], Akers et al. [2,3], Shah [26], Mikielewicz [25] and 
R134a

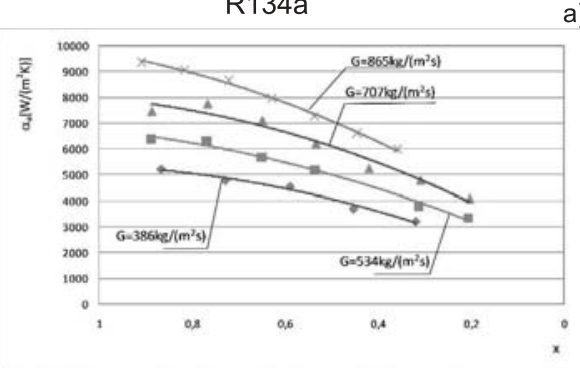

b)

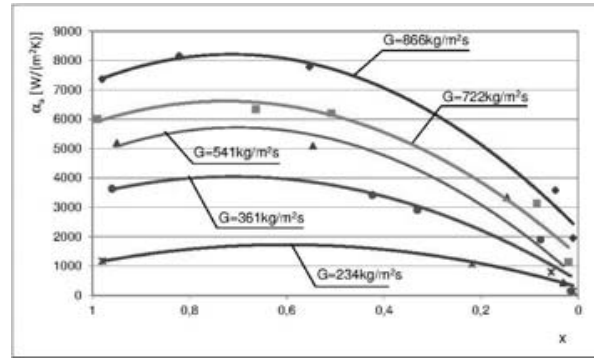

c)
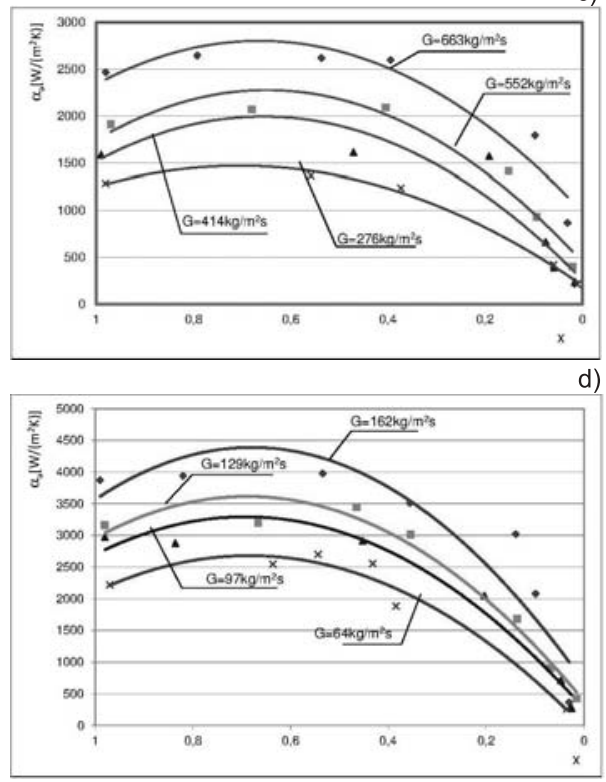

a)
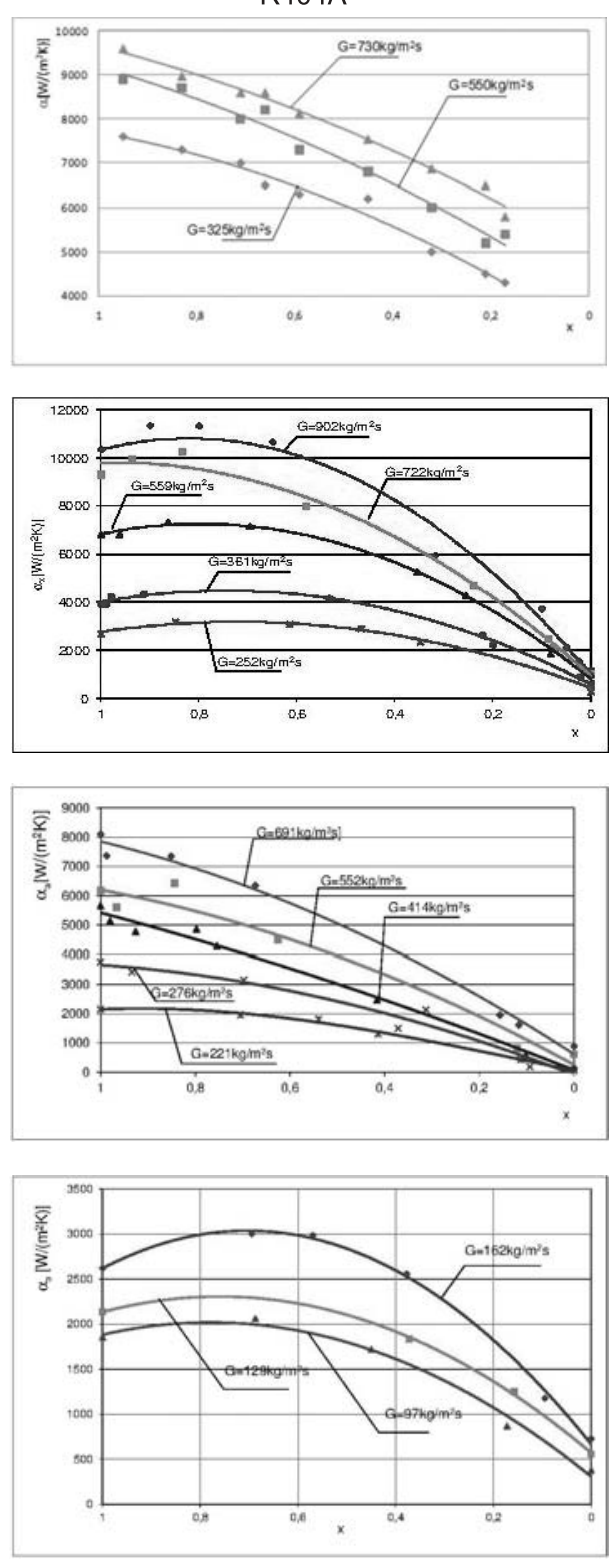

Figure 6. Results of experimental tests concerning the local heat transfer coefficient during the condensation of R134a and R404A in tubular minichannels with internal diameters: a) $d=0.98 \mathrm{~mm}$, b) $d=1.40 \mathrm{~mm}$, c) $d=1.60 \mathrm{~mm}$, and d) $d=3.30 \mathrm{~mm}$. 

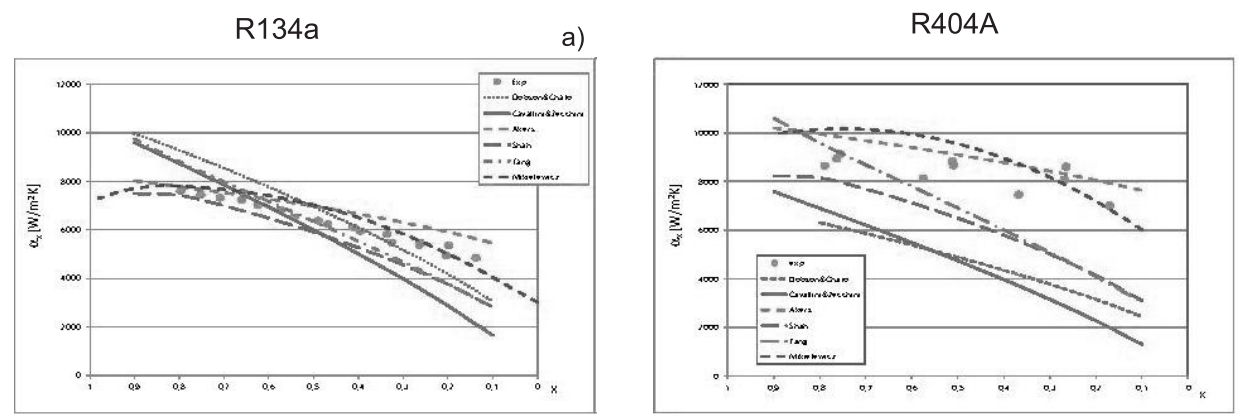

b)
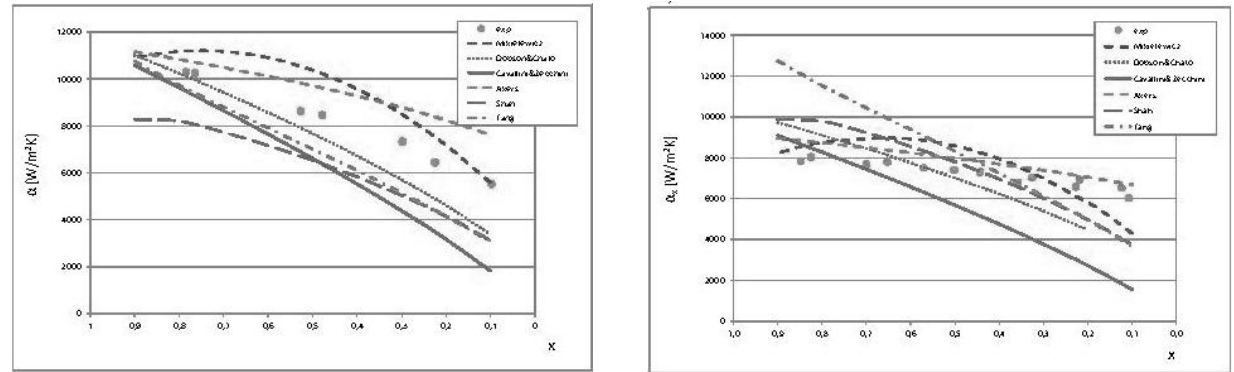

c)
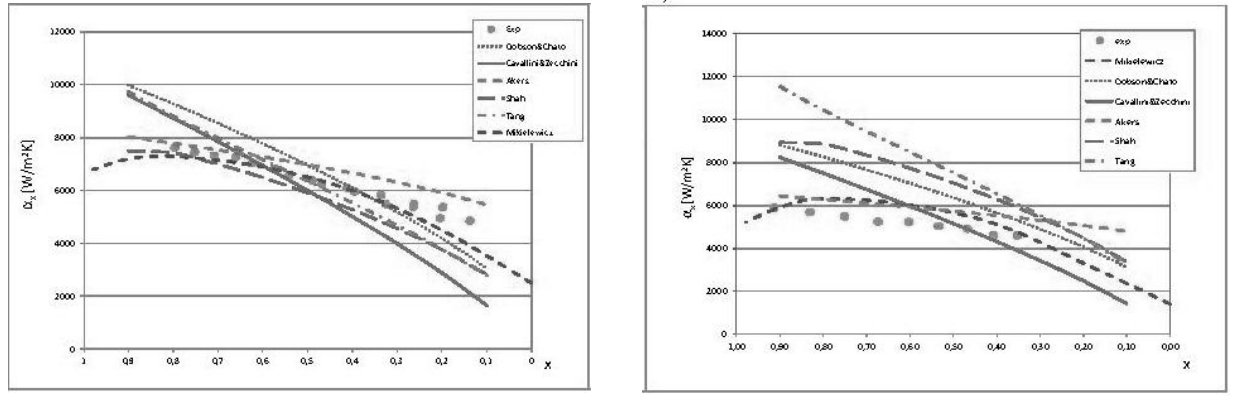

Figure 7. Comparison of the results of the experimental tests with the results of calculations according to the correlations proposed by other authors (Dobson and Chato [13], Cavallini and Zecchin [10], Akers et al. [2,3], Shah [26] and Tang [31], Mikielewicz [22], for $G=550-600 \mathrm{~kg} / \mathrm{m}^{2} \mathrm{~s}$ and the following minichannel internal diameters: a) $d=0.98 \mathrm{~mm}$, b) $d=1.40 \mathrm{~mm}$, and c) $d=2.30 \mathrm{~mm}$.

Tang [31]. It is important that when using the abovementioned selection of correlations in the range of the parameters with R134a, one may take into account the correlations according to Akers et al. [2,3] and Shah [26], though with certain reservations. This is particularly evident for R134a. The approximation accuracy not only depends on the internal diameter of 
the minichannel, but also on the refrigerant's mass flux density. For mass flux density $G<400-600 \mathrm{~kg} /\left(\mathrm{m}^{2} \mathrm{~s}\right)$, a good approximation is obtained from the results of the experiment and the calculation from the correlation of Akers et al. [2,3]. This is particularly evident concerning the range of minichannel diameters $d<1.40 \mathrm{~mm}$. For higher values of heat flux density $G>600 \mathrm{~kg} /\left(\mathrm{m}^{2} \mathrm{~s}\right)$, better results are obtained when using Shah's correlation [26]. Correlation of Mikielewicz [22] describe experimental investigations results with good accuracy in a part of experimental area. A list of comparisons is presented in Fig. 8, which confirms the abovementioned reservations. For the whole range of diameters $d=0.31-3.30 \mathrm{~mm}$ of the minichannels, with results are clearly visible; thus, the results of this comparisons are unsatisfactory, with the exception of comparison with Mikielewicz correlation.

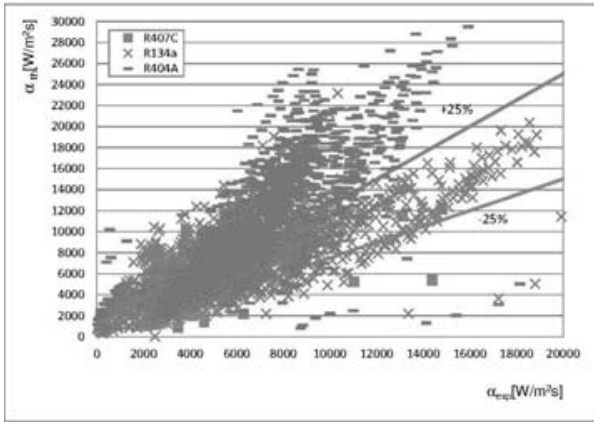

a)

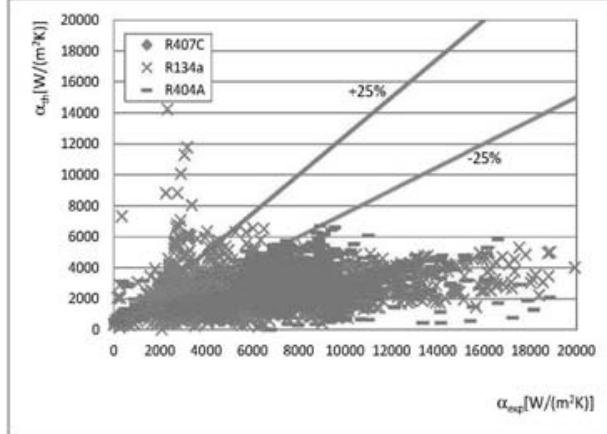

c)

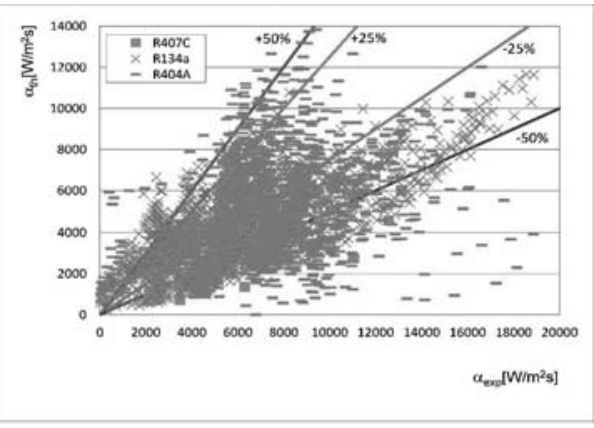

b)

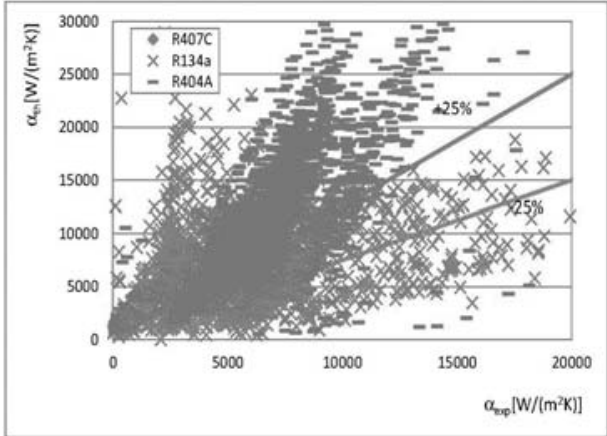

d)

Figure 8. Comparison of the results of the experimental investigations concerning the local heat transfer coefficient of R134a in minichannels with internal diameter $d=0.31-3.30 \mathrm{~mm}$ with the results of calculations according to the correlations of: a) Shah [26], b) Akers et al. [2,3], c) Thome [32], d) Tang [31]. 
A comparative analysis of the results of experimental investigations with the results of calculations according to the correlations by various authors demonstrated, in relation to the local heat transfer coefficient, that the application of the abovementioned correlations is limited. For this reason, the authors have developed their own experimental correlation with the use of mathematical statistics principles and with a selection of the model's parameters with quasi-Newton and simplex methods. An experimental correlation was obtained that describes the local heat transfer coefficient in the following form:

$$
\mathrm{Nu}_{x}=25.084 \operatorname{Re}_{l}^{0.258} \operatorname{Pr}_{l}^{-0.495} p_{r}^{-0.288}\left(\frac{x}{1-x}\right)^{0.266},
$$

hence

$$
\alpha_{x}=\frac{\mathrm{Nu}_{x} \lambda_{l}}{d}
$$

where

$$
p_{r}=\frac{p_{s}}{p_{c r}}
$$

is a reduced pressure, $p_{s}$ is a saturation pressure, and $p_{c r}$ is a critical pressure, $\lambda$ is the thermal conductivity coefficient, $\mathrm{Nu}, \mathrm{Pr}$ are the Nusselet and Prandl number, respectively.

Figure 9 presents a comparison of the results of experimental tests with the results of calculations from correlations (3) and (4). The results of the experimental tests fall within the range of $\pm 25 \%$. The developed experimental correlation was verified for the following refrigerants R134a, R404A and $\mathrm{R} 407 \mathrm{C}$ and a range of parameters $d=0.31-3.30 \mathrm{~mm} ; x=1-0 ; T_{s}=20$ $50^{\circ} \mathrm{C}$; and $G=100-1300 \mathrm{~kg} /\left(\mathrm{m}^{2} \mathrm{~s}\right)$. 


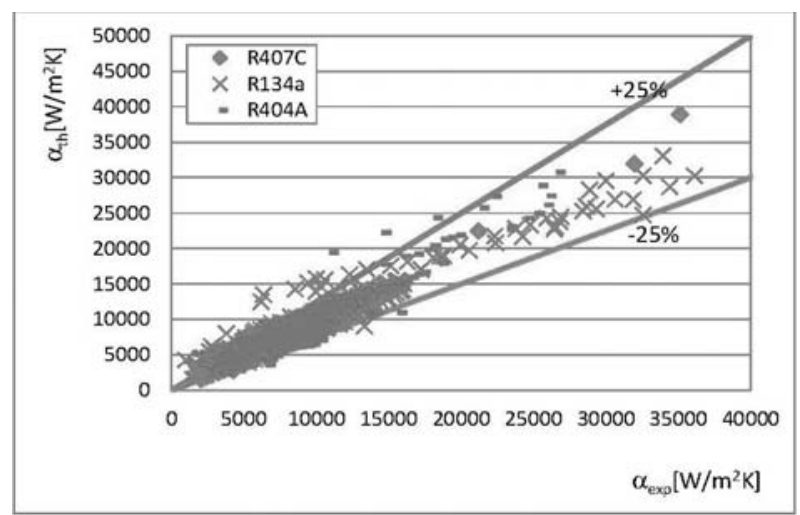

Figure 9. Comparison of the results of experimental tests concerning the local heat transfer coefficient, $\alpha_{x}$, during condensation of the refrigerants: R134a, R404A and $\mathrm{R} 407 \mathrm{C}$ in pipe minichannels with internal diameter $d=0.31-3.30 \mathrm{~mm}$ with the results of calculations from correlation (3).

\section{Conclusions}

1. Pipe minichannels can be used in the construction of compact refrigeration condensers. These are channels with a circular section, which in the condensation process of refrigerants intensify the heat transfer process while guaranteeing a high degree of structural compactness. The heat transfer coefficient is a measure of this intensification compared with conventional channels. Determination of the value of heat transfer coefficient and the pressure drop during this phase change constitutes the primary problem for designers.

2. The present paper provides comparative results of experimental tests concerning the condensation of refrigerants R134a, R404A and R407C in stainless steel pipe minichannels with internal diameters from 0.31 to $3.30 \mathrm{~mm}$.

3. A comparative analysis was conducted of the results of the experimental tests with the results of calculations from correlations proposed by other authors. It was demonstrated that, of these correlations, which serve to determine the local heat transfer coefficient, those proposed by Akers et al. [2,3] and Shah [26] can be used within a limited range depending on the internal diameter of the minichannel and the density of the mass flux of the refrigerant. It was demonstrated, however, that the area of their applications is limited. Mikielewicz correlation [22] 
describe experimental results with quite good accuracy and can by used, with limited range, to describe heat transfer coefficient during the condensation in minichannels.

4. An empirical correlation formula (3) was proposed on the basis of the investigations for the calculation of the local heat transfer coefficient within the range of two-phase flow structures, annular and annularstratified, for the following parameters: saturation temperature 30 $40^{\circ} \mathrm{C}$, quality $0-1$, and mass flux density $100-1300 \mathrm{~kg} /\left(\mathrm{m}^{2} \mathrm{~s}\right)$. The results of the experimental tests were within the range of $\pm 25 \%$ in relation to the values calculated from correlation expression (3).

Acknowledgement This study was conducted under Research Project No. N N512 456740.

Received 16 January 2012

\section{References}

[1] Akbar M.K., Plummer D.A., Giansian A.: On gas, liquid two-phase flow regimes in microchannels. Int. J. Multiphase Flow 29(2003), 855-865.

[2] Akers W., Deans O.K., Crosser O.K.: Condensation heat transfer within horizontal tubes. Chem. Eng. Prog. Symposium 54(1958), 89-90.

[3] Akers W., Deans O.K., Crosser O.K.: Condensation heat transfer within horizontal tubes. Chem. Eng. Prog. Symposium 55(1959), 171-176.

[4] Bandhauer T.M., Agarwal A., Garimella S.: Measurement and modelling of condensation heat transfer coefficients in circular microchannels. J. Heat Transfer 128(2006), 1050-1059.

[5] Baummer T., Cetegen E., Ohadi M., Dessiatoun S.: Force fed evaporation and condensation utilizing advanced microstructured surfaces and microchannels. Microelectronics J., 39(2008), 7, 975-980.

[6] Bohdal T., Kuczyński W.: Boiling of R404A refrigeration medium under the conditions of periodically generated disturbances. Heat Transfer Eng. 32(2010), 5, $359-368$.

[7] Bohdal T., Charun H., Sikora M.: Comparative investigations of the condensation of $R 134 a$ and $R 404 A$ refrigerants in pipe minichannels. Int. J. Heat Mass Transfer 54(2011), 1963-1974.

[8] Bohdal T., Charun H., Sikora M.: Heat transfer during the condensation of $R 134$ a refrigerant in pipe minichannels. In: Proc. 6th Int. Conf. on Transport Phenomena in Multiphase Systems (M.E. Poniewski, S. Alabrudziński eds.), Ryn, Poland, June 28 - July 02, 2011, 225-232. 
[9] Cavallini A., Doretti L., Matkovic M., Rossetto L.: Update on condensation heat transfer and pressure drop inside minichannels. In: Proc. ICMM2005, 3rd Int. Conf. on Microchannels and Minichannels, Toronto 2005.

[10] Cavallini A., Zecchin R.: A dimensionless correlation for heat transfer in forced convection condensation. In : Proc. 6th Int. Heat Transfer Conf., vol. 3, Tokyo 1974, 309-313.

[11] Cavallini A., Censi G., Del Col D., Doretti L., Longo G.A., Rossetto L.: Condensation of halogenated refrigerants inside smooth tubes. HVAC and Research 8(2002), 4, 429-451.

[12] Chang Y.J., Wang C.C.: A generalized heat transfer correlation for louvered fin geometry. Int. J. Refrigeration 40(1997), 3, 533-544.

[13] Dobson M.K., Chato J.C.: Condensation in smooth horizontal tubes. Trans ASME J. Heat Transfer ASME 120(1998), 193-213.

[14] Garcia-Cascales J.R., Vera-Garcia F., Gonzalez-Macia J., CorberanSalvador J.M., Johnson M.W., Kohler G.T.: Compact heat exchangers modelling: Condensation. Int. J. Refrigeration 33(2010), 1, 135-147.

[15] Giansian S.M.: Two-Phase Flow, Boiling and Condensation in Conventional and Miniature Systems. Cambridge University Press, 2008.

[16] Huhn J.: Void fraction with subcooled boiling. Recent Advances in Heat Transfer. Elsevier, Amsterdam 1992, 220-230.

[17] KANDLIKAR S.G.: Microchannels and minichannels - history, terminology, classification and current research needs. In: Proc. First Int. Conf. Microchannels and Minichannels, New York 2003.

[18] Kandlikar S.G., Garimella S., Li D., Colin S., King M.R.: Heat Transfer and Fluid Flow in Minichannels and Microchannels. Elsevier, 2006.

[19] Koyama S., Kuwahara K., Nakashita K., Yamamoto K.: Condensation of refrigerant in a multi-port channel. In: Proc. 1st Int. Conf. Microchannel and Minichannel, Rochester 2003, 193-205.

[20] Mehendale S.S., Jacobi A.M., Shah R.K.: Fluid flow and heat transfer at micro- and meso-scales with application to heat exchanger design. Appl. Mechanics Rev. 53(2000), 7, 175-193.

[21] Mikielewicz J.: Modelling od thermal-hydraulic processes. Ossolineum, Wrocław 1995 (in Polish).

[22] Mikielewicz J., Mikielewicz D.: A common method for calculation of flow boiling and flow condensation heat transfer coefficient in minichannels with account of nonadiabatic effects. Heat Transfer Eng. 32(2011), 1173-1181.

[23] Moser K., WebB R.L., NA B.: A new equivalent Reynolds number model for condensation in smooth tubes. J. Heat Transfer 120(1998), 410-417.

[24] Obhan C.B., Garimella S.: A comparative analysis of studies on heat transfer and fluid flow in microchannels. Microscale Thermophys 5(2001), 4, 293-311.

[25] Sнан R.K.: Classification of heat exchangers. In: Thermal Hydraulic Fundamentals and Design (S. Kakac, A.E. Bergles and F. Mayinger eds.), Hemisphere Publishing Corp., Washington D.C. 1986, 9-46. 
[26] Sнан M.M.: A general correlation for heat transfer during film condensation inside pipes. Int. J. Heat Mass Transfer 22(1979), 547-556.

[27] SHIn J.S., KIM M.H.: An experimental study of condensation heat transfer inside a minichannel with a new measurement technique. Int. J. Multiphase Flow 30(2004), 311-325.

[28] Sun L., Mishima K.: Evaluation analysis of prediction methods for two-phase flow pressure drop in minichannels. Int. J. Multiphase Flow 35(2009), 47-54.

[29] Tabatabatai A., Faghri A.: A new two-phase flow map and transition boundary accounting for surface tension effects in horizontal miniature and microtubes. Int. J. Heat Transfer 123(2001), 958-968.

[30] Tandon T.N., Varrna H.K., Gupta C.P.: New flow regimes map for condensation inside horizontal tubes. J. Heat Transfer 104(1982), 4, 763-768.

[31] TANG L.: Empirical study of new refrigerant flow condensation inside horizontal smooth and micro-fin tubes. PhD thesis, University of Maryland, College Park 1997.

[32] Thоме J.R.: Engineering Data Book III, Chap. 8: Condensation inside tubes. Wolverine Tube Inc., 2008.

[33] Thome J.R., Hajal J.El, Cavallini A.: Condensation in horizontal tubes. Part 1: two-phase flow pattern map. Int. J. Heat Mass Transfer 46(2003), 18, 3349-3363.

[34] Thome J.R., Hajal J.El, Cavallini A.: Condensation in horizontal tubes, part 2: new heat transfer model based on flow regimes. Int. J. Heat Mass Transfer 46(2003), 18, 3365-3387.

[35] YAN Y.Y., LiN T.F.: Condensation heat transfer and pressure drop of refrigerant R134a in small pipe. Int. J. Heat Mass Transfer 42(1999), 697-708.

[36] Yang C., WebB R.: A predictive model condensation in small hydraulic diameter tubes having axial microfin. Trans. ASME J. 119(1997), 776-782.

[37] Wang W.W., Radcliff T.D., Christensen R.N.: A condensation heat transfer correlation for millimetre - scale tubing with flow regime transition. Exp. Therm. Fluid Sci. 26(2002), 473-485.

[38] Webb R.L., Zhang M., Narayana A., Murthy R.: Condensation heat transfer in small diameter tubes. In: Proc. 11th Int. Heat Transfer Conf. Koyongju, Korea: Heat Transfer 1998.

[39] Wilson M.J., Newell T.A., Chato J.C., Ferreira C.A.: Refrigerant charge, pressure drop and condensation heat transfer in flattened tubes. Int. J. Refrig. 26(2003), 4, 442-451. 